\title{
The effects of previous open renal stone surgery types on PNL outcomes
}

\author{
Faruk Ozgor, MD; Onur Kucuktopcu, MD; Burak Ucpinar, MD; Omer Sarilar, MD; Akif Erbin, MD; \\ Fatih Yanaral, MD; Murat Sahan, MD; Murat Binbay, MD
}

Haseki Training and Research Hospital, Istanbul, Turkey

Cite as: Can Urol Assoc J 2016;10(7-8):E246-50. http://dx.doi.org/10.5489/cuaj.3687 Published online July 12, 2016

\section{Abstract}

Introduction: Our aim was to demonstrate the effect of insicion of renal parenchyma during open renal stone surgery (ORSS) on percutaneous nephrolithotomy (PNL) outcomes.

Methods: Patients with history of ORSS who underwent PNL operation between June 2005 and June 2015 were analyzed retrospectively. Patients were divided into two groups according to their type of previous ORSS. Patients who had a history of ORSS with parenchymal insicion, such as radial nephrotomies, anatrophic nephrolithotomy, lower pole resection, and partial nephrectomy, were included in Group 1. Other patients with a history of open pyelolithotomy were enrolled in Group 2. Preoperative characteristics, perioperative data, stone-free status, and complications were compared between the groups. Stone-free status was defined as complete clearance of stone(s) or presence of residual fragments smaller than $4 \mathrm{~mm}$. The retrospective nature of our study, different experience level of surgeons, and lack of the evaluation of anesthetic agents and cost of procedures were limitations of our study. Results: 123 and 111 patients were enrolled in Groups 1 and 2 , respectively. Preoperative characteristics were similar between groups. In Group 1, the mean operative time was statistically longer than in Group $2(p=0.013)$. Stone-free status was significantly higher in Group 2 than in Group $1(p=0.027)$. Complication rates were similar between groups. Hemorrhage requiring blood transfusion was the most common complication in both groups $(10.5 \%$ vs. $9.9 \%$ ).

Conclusions: Our study demonstrated that a history of previous ORSS with parenchymal insicion significantly reduces the success rates of PNL procedure.

\section{Introduction}

Percutaneous nephrolithotomy (PNL) has become the primary treatment option for renal stone(s) larger than $2 \mathrm{~cm}$ and staghorn calculi. ${ }^{1}$ Previously published articles have shown that PNL provides high stone-free rates and high patient compliance, with acceptable complication rates. However, certain patient groups, such as morbidly obese patients, patients with anomalous kidney, and patients with a history of open renal stone surgery (ORSS), require special attention before choosing PNL as the preferred treatment option. ${ }^{2,3}$

It is clear that previous ORSS is related with pelvicalyceal distortion, bowel displacement, and retroperitoneal scarring, which may affect PNL outcomes. However, results of studies investigating the effect of ORSS on PNL outcomes are controversial. ${ }^{4}$ When we analyzed previous studies on the effect of ORSS on PNL, we found that open pyelolithotomy, open nephrolithotomy, open nephropyelolithotomy, and partial nephrectomy for a non-functional part of the kidney were all grouped as ORSS. For the first time, our study categorizes patients who have undergone PNL procedure according to the types of previous ORSS. We aimed to demonstrate the effect of insicion of renal parenchyma during ORSS on PNL outcomes.

\section{Methods}

A total of 341 patients with a history of ORSS who underwent PNL procedure for kidney stone(s) between June 2005 and June 2015 were analyzed retrospectively. Patient characteristics, including age, gender, body mass index (BMI), degree of hydronephrosis, and type of ORSS, were recorded. Also, size, number, and location of stone(s) were listed. Hemoglobin level, serum creatinine level, platelet count, and coagulation screening tests were assessed preoperatively in every patient. Kidney and stone characteristics were evaluated by intravenous urography (IVU) and/or abdominal computed tomography (CT). Sterile urine culture was obtained from all patients before surgery.

In this study, patients who underwent PNL with a history of ORSS were divided into two groups according to the type of ORSS. Patients with a history of ORSS with parenchymal insicion (radial nephrotomies, anatrophic nephrolithotomy, lower pole resection, partial nephrectomy) were included in Group 1 (open nephrolithotomy group). Patients with 
a history of open pyelolithotomy were enrolled in Group 2. Patients who underwent multiple ORSS or nephropyelolithotomy operation were excluded from the study. Also, having a congenital renal abnormality (e.g., ureteropelvic junction obstruction, horseshoe, or ectopic kidney) and/or being age less than 18 years were other exclusion criteria. Finally, patients with inadequate data on their type of ORSS were excluded.

\section{Technique}

A standardized PNL procedure was performed in all cases. Percutaneous access was performed with an 18-G needle under C-arm fluoroscopy in prone position. A high-pressure balloon dilator (Nephromax ${ }^{\mathrm{TM}}$ Microvasive, Boston Scientific Corporation, Natick, MA, U.S.) or telescopic dilatators were used for tract dilatation. Stone(s) were fragmanted with an ultrasonic lithotripter (Swiss Lithoclast ${ }^{\circledR}, \mathrm{EMS}$ Electro Medical System, Nyon, Switzerland) or pneumatic lithotripter (Vibrolith ${ }^{\circledR}$, Elmed, Ankara, Turkey). At the end of each procedure, a 14-F nephrostomy tube was placed. The operative time was calculated as the time from the puncture of the pelvicaliceal system to the final placement of a nephrostomy tube.

Stone-free status was assessed with kidney-ureter-bladder $X$-ray (KUB) on first postoperative day and abdominal CT scan at three months postoperatively. Stone-free status was defined as complete clearance of stone(s) or presence of residual fragments smaller than $4 \mathrm{~mm}$.

During statistical analyses, values were evaluated as numbers, means, percentages, and intervals. Numbers and percentages were compared using Chi-square test. Before the comparison of mean values, the values were evaluated for homogenity. Homogenously distributed values were compared using Student T-test and heterogenously distributed values were compared using Mann-Whitney U-test. Additionally, univariate and multivariate analyses were done in order to compare the effect of different ORSS types on PNL outcomes.

\section{Results}

After our evaluation, 123 and 111 patients were enrolled in Groups 1 and 2, respectively. Demographic characteristics, including age, gender, BMI, and operation side were similar between groups. The mean stone size and degree of hydronephrosis were higher in Group 1, but the differences were not statistically significant $(p=0.568$ vs. $p=0.092$ ). The mean interval between previous ORSS and PNL surgery was 81.3 and 79.2 months in Groups 1 and 2, respectively $(p=0.210)$. Also, stone location was comparable between groups $(p=0.864)$. Patient characteristics are listed in Table 1.

\begin{tabular}{|c|c|c|c|}
\hline & \multicolumn{2}{|c|}{ Type of previous open surgery } & \multirow[b]{2}{*}{ p value } \\
\hline & Nephrolitotomy & Pyelolithotomy & \\
\hline Number & 123 & 111 & \\
\hline Gender & & & 0.648 \\
\hline Male & 80 & 69 & \\
\hline Female & 43 & 42 & \\
\hline Age $^{*}$ (years) & $45.4 \pm 13.5$ & $43.4 \pm 14.9$ & 0.280 \\
\hline $\begin{array}{l}\text { Body mass index* } \\
\left(\mathrm{kg} / \mathrm{m}^{2}\right)\end{array}$ & $26.3 \pm 4.0$ & $24.9 \pm 4.0$ & 0.054 \\
\hline Interval between & & & \\
\hline $\begin{array}{l}\text { ORSS and PNL } \\
\text { (months) }\end{array}$ & $81.3 \pm 11.2$ & $79.2 \pm 14.5$ & 0.210 \\
\hline Stone area* $\left(\mathrm{cm}^{2}\right)$ & $8.5 \pm 7.1$ & $8.1 \pm 5.8$ & 0.568 \\
\hline Stone location & & & 0.864 \\
\hline Multiple calyx & 68 & 58 & \\
\hline Pelvis & 23 & 26 & \\
\hline Lower & 25 & 22 & \\
\hline Middle & 2 & 1 & \\
\hline Upper & 5 & 4 & \\
\hline \multicolumn{4}{|l|}{ Nephrolitotomy type } \\
\hline Radial nephrotomy & 83 & & \\
\hline $\begin{array}{l}\text { Anatrophic } \\
\text { nephrolithotomy }\end{array}$ & 26 & & \\
\hline $\begin{array}{l}\text { Lower pole } \\
\text { resection }\end{array}$ & 5 & & \\
\hline Partial nephrectomy & 9 & & \\
\hline Operation side & & & 0.233 \\
\hline Left & 65 & 50 & \\
\hline Right & 58 & 61 & \\
\hline $\begin{array}{l}\text { Degree of } \\
\text { hydronephrosis }\end{array}$ & & & 0.092 \\
\hline 0 & 6 & 10 & \\
\hline 1 & 30 & 25 & \\
\hline 2 & 71 & 60 & \\
\hline 3 & 16 & 16 & \\
\hline \multicolumn{4}{|l|}{ Stone opacity } \\
\hline Non-opaque & 9 & 3 & 0.093 \\
\hline Opaque & 112 & 106 & \\
\hline Semi-opaque & 2 & 2 & \\
\hline
\end{tabular}

The mean operative time in Group 1 was statistically longer than in Group $2(p=0.013)$. There was no significant difference in number of accesses and access locations, ( $p=0.495$ vs. $p=0.514$, respectively). The mean hemoglobin drop was $1.9 \pm 1.4$ in Group 1 and $1.8 \pm 1.3$ in Group 2 $(p=0.585)$. Perioperative and postoperative data are shown in Table 2.

In total, 48 complications occurred in 234 patients. Hemorrhage requiring blood transfusion was the most common complication in both groups $(10.5 \%$ vs. $9.9 \%$ in Groups 1 and 2, respectively). Angioembolization was performed 


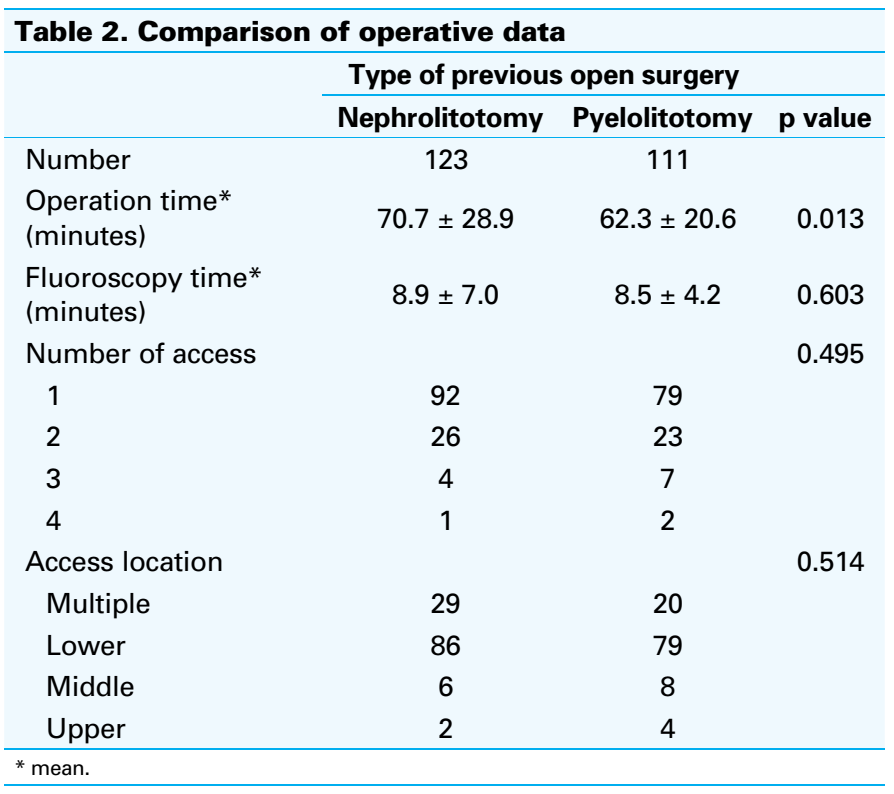

for only one patient in Group 1. Due to either the presence of extravasation in postoperative nephrostography or an obstruction in the ureter, postoperative JJ stent was placed in nine patients $(7.3 \%)$ in Group 1 and four patients (3.6\%) in Group 2. Postoperative fever rates were similar between groups (3.3\% vs 5.4\% in Groups 1 and 2, respectively). No pulmonary complications or colonic injuries were seen.

Stone-free status was significantly higher in Group 1 than in Group $2(p=0.027)$ (Table 3). Univariate analysis revealed that age $(p=0.80), B M I(p=0.30)$, degree of hydronephrosis $(p=0.32)$, localization of the stone $(p=0.28)$, stone opacity $(p=0.80)$, and history of previous shockwave lithotripsy (SWL) sessions $(p=0.36)$ did not affect the PNL success rates. Stone size and previous ORSS type significantly affected the PNL success rates $(p=0.02$ and $p=0.01$, respectively, in univariate analysis; and $p=0.01$ and $p=0.01$, respectively, in multivariate analysis).

\section{Discussion}

Ozgor et al have previously compared the outcomes of primary PNL patients with patients who have undergone ORSS and PNL, and have demonstrated that history of ORSS reduces the success rates of PNL. ${ }^{5}$ While analyzing the data of patients with previous ORSS, they realized that the type of previous ORSS also affects the results of further PNL procedures. Although there are many types of ORSS, previous studies in the literature categorized ORSS types into one single group. The current study divides ORSS into two groups according to the presence or absence of parenchymal incision.

Although both open nephrolithotomy and open pyelolithotomy aim to remove renal stone(s) under direct vision, there are significant differences between these two surgical

\begin{tabular}{|c|c|c|c|}
\hline & \multicolumn{2}{|c|}{ Type of previous open surgery } & \multirow[b]{2}{*}{$\begin{array}{c}\mathbf{p} \\
\text { value }\end{array}$} \\
\hline & Nephrolitotomy & Pyelolitotomy & \\
\hline Number & 123 & 111 & \\
\hline $\begin{array}{l}\text { Removal time of } \\
\text { nephrostomy (days) }\end{array}$ & $3.0 \pm 1.7$ & $2.6 \pm 1.5$ & 0.095 \\
\hline $\begin{array}{l}\text { Hospitalization time* } \\
\text { (days) }\end{array}$ & $2.9 \pm 2.2$ & $2.9 \pm 1.1$ & 0.820 \\
\hline $\begin{array}{l}\text { Hemoglobin drop* } \\
\text { (g/dl) }\end{array}$ & $1.9 \pm 1.4$ & $1.8 \pm 1.3$ & 0.585 \\
\hline Balon dilatation failure & 0 & 0 & \\
\hline $\begin{array}{l}\text { Postoperative } \\
\text { complications }\end{array}$ & & & 0.709 \\
\hline Fever & 4 & 6 & \\
\hline Transfusion need & 13 & 11 & \\
\hline Angioembolisation & 1 & 0 & \\
\hline $\begin{array}{l}\text { Pulmonary } \\
\text { complications }\end{array}$ & 0 & 0 & \\
\hline $\begin{array}{l}\text { Postoperative JJ } \\
\text { insertion }\end{array}$ & 9 & 4 & \\
\hline Bowel injury & 0 & 0 & \\
\hline Success & & & 0.027 \\
\hline Residual fragment & $34(28 \%)$ & $20(18 \%)$ & \\
\hline Stone-free status & $89(72 \%)$ & $91(82 \%)$ & \\
\hline $\begin{array}{l}\text { Stone-free status } \\
\text { according to previous } \\
\text { ORSS type }\end{array}$ & & & \\
\hline Radial nephrotomy & $62(74.6 \%)$ & & \\
\hline $\begin{array}{l}\text { Anatrophic } \\
\text { nephrolithotomy }\end{array}$ & $18(69.2 \%)$ & & 0.820 \\
\hline $\begin{array}{l}\text { Lower pole } \\
\text { resection }\end{array}$ & $3(60.0 \%)$ & & \\
\hline Partial nephrectomy & $6(66.6 \%)$ & & \\
\hline
\end{tabular}

techniques. Open nephrolithotomy allows for greater access to calyces. However, during open nephrolithotomy, peeling of Gerota's fascia and insicion of renal parenchyma may result in more fragile kidney tissue and more extensive fibrosis in the retroperitoneal space. Additionally, the probability of infundibular stenosis is relatively high after open nephrolithotomy. ${ }^{6,7}$

Viville et al and Jones et al reported significantly lower PNL success after ORSS. ${ }^{8,9}$ However, more recent studies — such as those by Tugcu et al and Resorlu et al — did not find any significant difference in PNL success, with or without previous ORSS. ${ }^{10,11}$ The success rate of patients with previous open pyelolithotomy was $82 \%$ in our study; however, the rate decreased to $72 \%$ in patients with a history of open nephrolithotomy. We postulate that presence of fragile kidney tissue, distorted calyx anatomies, and extensive fibrosis following open nephrolithotomy may be the reasons for this outcome. 
Our study revealed significantly longer operative times in the open nephrolithotomy group when compared with the open pyelolithotomy group (70.7 minutes vs. 62.3 minutes). Previous articles investigating this topic had controversial results. The mean operative time in the Sofikerim et al and Falahatkar et al studies were 70.2 minutes and 74.5 minutes, respectively; these are similar results to our study. ${ }^{12,13}$ However, Kurtulus et al reported that their mean operative time was 158 minutes. ${ }^{14}$ None of these studies subdivided the types of ORSS as nephrolithotomy or pyelolithotomy. Difficulties during manipulations of the nephroscope in distorted calyx anatomy could increase the operative time. Additionally, hemorrhagic events may easily ocur in fragile epithelia, which deteriorates visualization. Focusing and fragmentation of the stone is a time-consuming process under poor vision.

In Yesil's study, mean hospitalization time was 1.97 and 2.06 days in patients with and without previous ORSS, respectively. ${ }^{15}$ Sofikerim et al and Kurtulus et al did not report any unfavourable effect of previous ORSS on hospitalization time after PNL; however, their hospitalization times were much longer when compared with Yesil's study (4.4 vs. 4.2 days and 3.7 vs. 3.3 days, respectively). ${ }^{12,14}$ In the current study, we have not found any statistically significant difference in hospitalization time between patients with previous open nephrolithotomy and previous open pyelolithotomy surgery $(p=0.820)$. We emphasize that perioperative or postoperative complications are generally related to hospitalization time rather than technical difficulties.

Blood transfusion and angioembolisation rates after PNL are $2-45 \%$ and $0.8 \%$, respectively. ${ }^{16}$ Bleeding necessating blood transfusion was the most common complication in our study and occured in 24 of 234 patients. Although, mean hemoglobin drop was slightly higher in the open nephrolithotomy group, the difference was not statistically significant $(1.9 \mathrm{~g} / \mathrm{dl}$ vs. $1.8 \mathrm{~g} / \mathrm{dl})$. Likewise, blood transfusion rates were similar between groups (13 vs. 11 patients in Groups 1 and 2 , respectively). Only one patient in Group 1 required angioembolization.

We believe that renal parenchymal incision leads to neovascularization in renal tissue and this may resut in a more fragile renal parenchyma, which could be the cause of increased bleeding rates. Moreover, pelvicaliceal distortion and infundibular stenosis may facilitate bleeding during manipulation of the nephroscope.

Postoperative fever rate was 3.3\% in Group 1 and 5.4\% in Group 2; this is significantly lower than with other studies. Sofikerim et al and Falahatkar et al reported $33.3 \%$ and $11 \%$ fever rates, repectively, in their patients with previous ORSS. ${ }^{12,13}$ Sterile urine cultures were obtained from every patient prior to surgery. Additionally, we finalzed the PNL procedure if purulent urine discharge was observed from the nephrostomy tract, which may explain our lower fever rates. We did not face any pleural complications in either group, mimicking results seen in studies by Resorlu et al and Onal et al, who did not find any significant correlation between previous ORSS and pleural complications. ${ }^{11,17}$

Previous ORSS is related to increased risk of colonic injury because of colonic displacement. Kurtulus et al used ultrasonography to detect malposition of colon in patients with previous ORSS. Also, they reported that they protect themselves from radiation exposure by using ultrasonography. ${ }^{14}$ Gedik et al instead recommended abdominal CT to identify colon disposition and to avoid colonic injury in PNL. ${ }^{18}$ Our policy was to perform abdominal CT in patients with previous ORSS to assess colonic malposition, which may explain the absence of colonic injury in our study.

In some cases, retroperitoneal scars may cause difficulties during the dilatation process in patients with a history of ORSS. Sharp insicion of fascia could be a solution for this problem. Also, use of otis urethrotome over a guidewire could be an alternative solution. ${ }^{19}$ According to Shah et al, use of telescopic dilators are an appropriate option. ${ }^{20}$ Some authors recommend metal dilators in the presence of serious retroperitoneal scars. ${ }^{21}$ In our study, most of our cases were performed with balloon dilators without any failure. We performed telescopic dilators in only 23 patients $(12$ in Group 1 and 11 in Group 2) to gain surgical experience and when we didn't have access to balloon dilatators. We believe that both balloon dilators and telescopic dilators are safe and effective alternatives in patients with previous ORSS, regardless of previous ORSS type.

Our study has some limitations. First, it is of a retrospective nature. Second, operations were performed by different surgeons, including residents and specialists, which may influence PNL outcomes. Additionally, we did not analyze the effect of previous ORSS type on use of anesthetic agents and cost of procedures. Lastly, we routinely placed a nephrostomy tube at the end of each operation, therefore, further studies that include tubeless PNL procedures is necessary to evaluate the effect of previous ORSS type on PNL results.

\section{Conclusion}

Our study has demonstrated that a history of open nephrolithotomy significantly reduces PNL success rates with a prolonged operation time, when compared with history of open pyelolithotomy. We believe that prospective, randomized studies with long-term results will provide a better understanding of the importance of previous ORSS type on PNL outcomes.

Competıng interests: The authors declare no competing personal or financial interests. 
Ozgor et al.

Acknowledgement: All procedures performed in studies involving human participants were in accordance with the ethical standards of the institutional and/or national research committee and with the 1964 Helsinki declaration and its later amendments or comparable ethical standards. Informed consent was obtained from all individual participants included in the study.

This paper has been peer-reviewed.

\section{References}

1. Preminger GM, Assimos DG, Lingeman JE, et al. AUA Nephrolithiasis Guideline Panel: Chapter 1: AUA guideline on management of staghorn calculi: Diagnosis and treatment recommendations. J Urol 2005;173:1991-2000. http://dx.doi.org/10.1097/01.ju.0000161171.67806.20

2. Srisubat $A$, Potisat $S$, Lojanapiwat $B$, et al. Extracorporeal shock wave lithotripsy (ESWL) vs. percutaneous nephrolithotomy (PCNL) or retrograde intrarenal surgery (RIRS) for kidney stones. Cochrane Database Syst Rev 2014;24;11. http://dx.doi.org/10.1002/14651858.cd007044.pub3

3. Binbay $M$, Istanbulluoglu 0 , Sofikerim $M$, et al. Effect of simple malrotation on percutaneous nephrolithotomy: A matched pair multicenter analysis. J Urol 201 1;185:1737-41. http://dx.doi.org/10.1016/i. juro.2010.12.060

4. Kamphuis GM, Baard J, Westendarp M, et al. Lessons learned from the CROES percutaneous nephrolithotomy global study. World J Urol 2015;33:223-33. http://dx.doi.org/10.1007/s00345-014-1367-5

5. Ozgor F, Kucuktopcu 0 , Sarllar 0 , et al. Does previous open renal surgery or percutaneous nephrolithotomy affect the outcomes and complications of percutaneous nephrolithotomy. Urolithiasis 2015;43:541-7. http://dx.doi.org/10.1007/s00240-015-0798-9

6. Melissourgos ND, Davilas EN, Fragoulis A, et al. Modified anatrophic nephrolithotomy for complete staghorn calculus disease — does it still have a place? Scand I Urol Nephrol 2002;36:426-30. http://dx.doi. org/10.1080/003655902762467576

7. Honeck $P$, Wendt-Nordahl $G$, Krombach $P$, et al. Does open stone surgery still play a role in the treatment of urolithiasis? Data of a primary urolithiasis centre. J Endourol 2009;23:1209-12. http://dx.doi. org/10.1089/end.2009.0027

8. Viville C. Percutaneous nephrolithotomy: Personal experience in 100 cases. J Urol 1987;93:253-8.

9. Jones DJ, Russell GL, Kellett MJ, et al. The changing practice of percutaneous stone surgery: Review of 1000 cases 1981-1988. Br J Urol 1990;66:1-5. http://dx.doi.org/10.1111/j.1464-410X.1990. tb14852.x
10. Tugcu V, Su FE, Kalfazade N, et al. Percutaneousnephrolithotomy (PCNL) in patients with previous open stone surgery. Int Urol Nephrol 2008;40:881-4. http://dx.doi.org/10.1007/s1 1255-008-9376-1

11. Resorlu B, Kara C, Senocak C, et al. Effect of previous open renal surgery and failed extracorporeal shockwave lithotripsy on the performance and outcomes of percutaneous nephrolithotomy. J Endourol 2010;24:13-6. http://dx.doi.org/10.1089/end.2009.0291

12. Sofikerim M, Demirci D, Gulmez I, et al. Does previous open nephrolithotomy affect the outcome of percutaneous nephrolithotomy. J Endourol 2007;21:401-3. http://dx.doi.org/10.1089/end.2006.0293

13. Falahatkar S, Panahandeh Z, Ashoori E, et al. What is the difference between percutaneous nephrolithotomy in patients with and without previous open renal surgery? J Endourol 2009;23:1 107-10. http://dx.doi. org/10.1089/end.2008.0630

14. Kurtulus FO, Fazlioglu A, Tandogdu Z, et al. Percutaneous nephrolithotomy: Primary patients vs. patients with history of open renal surgery. J Endourol 2008;22:2671-5. http://dx.doi.org/10.1089/ end.2007.0431

15. Yesil $\mathrm{S}$, Ozturk U, Goktug $\mathrm{HN}$, et al. Previous open renal surgery increased vascular complications in percutaneous nephrolithotomy (PCNL) compared with primary and secondary PCNL and extracorporeal shockwave lithotripsy patients: a retrospective study. Urol Int 2013;91:331-4. http://dx.doi. org/10.1159/000351968

16. Kessaris DN, Bellman GC, Pardalidis NP, et al. Management of hemorrhage after percutaneous renal surgery. J Urol 1995;153:604-8. http://dx.doi.org/10.1016/S0022-5347(01)67659-6

17. Onal B, Gevher F, Argun B, et al. Does previous open nephrolithotomy affect the outcomes and complications of percutaneous nephrolithotomy in children? J Pediatr Urol 2014;10:730-6. http://dx.doi. org/10.1016/i.jpurol.2013.11.021

18. Gedik A, Tutus A, Kayan D. Percutaneous nephrolithotomy in pediatric patients: Is computerized tomography a must? Urol Res 2011;39:45-9. http://dx.doi.org/10.1007/s00240-010-0272-7

19. Patel RP, Hawan MD, Gupta S. Technical difficulties during PCNL in previously operated kidney: 38 cases. $J$ Endourol 2004;18:A150.

20. Shah HN, Mahajan AP, Hegde SS, et al. Tubeless percutaneous nephrolithotomy in patients with previous ipsilateral open renal surgery: A feasibility study with review of literature. J Endourol 2008; 22:19-24. http://dx.doi.org/10.1089/end.2006.0480

21. Kaufman JD, Shah 0. Balloon dilation for establishing percutaneous renal access in complex cases: Incidence of and risks for failure. J Endourol 2006;20:A19.

Correspondence: Dr. Faruk Ozgor, Haseki Training and Research Hospital, Department of Urology, Fatih, Istanbul, Turkey; md.farukozgor@yahoo.com 